\title{
Más que discutible
}

De Oscar Tusquets siempre me interesó más su verbo que su obra, hasta que conocí su obra y la viví. La viví durante una generosa comida en casa del fotógrafo Leopoldo Pomés en Gràcia. En el jardín, o dentro de sus espacios proporcionados y simétricos, se siente uno mejor, mejor persona, mejor que fuera de aquella casa, a pesar seguramente de su estilo renacentista, premeditadamente burgués. Se siente uno bien, a pesar precisamente de eso, de su estilo. Pero es el propio Tusquets el que se encarga de recordarnos a todos en su libro que esto, el estilo, la imagen, el arte en definitiva es "más que discutible". Por eso en rita_nos acercamos para oler los espacios, para vivirlos y para poder decir por qué no publicamos aquella casa o aparece esta otra. Pretendemos estar íntimamente ligados a la experiencia del lugar.

El trabajo de editor es una fábrica de enemigos. Por eso me sorprende, cada número, que algunos amigos quieran entrar en esta fábrica viviendo tan a gusto en sus oficinas, en sus talleres, en sus estudios, en sus universidades. Al fin y al cabo nosotros regresamos a España pero Roberto permanece, se queda allí, entre todos aquellos que no hemos podido incluir.

Tal vez no le guste a mi amigo Nicolás esta confesión, pero saliendo en coche desde Rosario hacia Córdoba y después de tres horas le pregunté: “¿Cuántos editores han venido a ver la Capilla?" - probablemente la obra argentina más publicada de los últimos años - "¿Cuantos arquitectos? ¿Cuantos compañeros?"

"Ninguno" -me dijo -.

"Sin embargo ha venido mucha gente, gente de los pueblos de alrededor, peregrinos de Córdoba, de otros lugares. Se sienten bien aquí".

Camino de vuelta, y en el calor de la visita, le pude decir: "Nicolás, a partir de la Capilla te has convertido, para mí, en el mejor arquitecto de la historia contemporánea de Rosario" - que me perdonen Scrimaglio, Rafael Iglesia, Caballero, El negro Villafañe... grandes todos -.

Se rio y me contestó: "Bueno...tendré que hacer otra obra para regresar a mi lugar".

Tanto más que discutible puede resultar una selección hecha entre dos donde el desempate no existe y lo discutible forma parte del axioma. Con estas circunstancias se encontró otro antiguo amigo, Roberto Busnelli, que reflexiona sobre la experiencia a continuación:

Como plantea Arturo, "construir" una selección siempre resulta un dilema difícil de abordar, para ello siempre es necesario establecer alguna coherencia o lógica que respalde una "lectura final" que, aunque siempre termina teniendo una gran carga de subjetividad y arbitrariedad, requiere un gran esfuerzo de síntesis. En este caso la dificultad se ve acrecentada cuando dicha selección involucra la arquitectura de un país tan grande, diverso y complejo como la Argentina. Para ello, como estrategia, realizamos un primer recorte que involucra solo a tres ciudades, primera decisión que también sería opinable: Buenos Aires, Rosario y Córdoba. Dos ciudades costeras y una mediterránea que concentran algunos de los centros urbanos más densamente poblados del país. Cada una de ellas con características geográficas, climáticas, sociales y culturales bien definidas que impactan en la forma de pensar y hacer arquitectura.

En Buenos Aires, como en toda metrópolis global, el actual panorama del proyecto residencial nos ofrece una inmediata reflexión: el abandono del problema residencial como núcleo de reflexión e investigación está conduciendo a la apatía y banalidad dominantes en la gran mayoría de los edificios destinados a vivienda, sean estos por encargo público o fruto de la especulación privada. 
Esta actitud impacta tanto en los edificios de carácter icónico como en aquellos que "construyen el tejido" de la ciudad. Dentro de este último grupo destacamos tres propuestas que, a pesar de las restricciones que imponen tanto las dimensiones de los lotes como la normativa vigente, fundan en una actitud desprejuiciada la piedra fundamental a la hora de definir implantaciones o la forma de relacionarse con la ciudad construida. En una de las visitas, Alexis y Juan, del grupo Monoblock, nos muestran entusiasmados las nuevas relaciones espaciales generadas por terrazas y espacios intermedios internos que desafían, incluso, a la propia normativa. Espacios frescos, llenos de vegetación y vitalidad, espacios no programados o, mejor dicho, sin programa aparente, como en las expansiones del edificio ZLA o el acceso a las viviendas del Pasaje Cabrer en Palermo, son los que articulan las vivencias que proponen estos proyectos versus la ciudad existente.

En definitiva, lo que nos queda claro es que, lejos de ensalzar la diferencia, estas propuestas enfatizan que el proyecto colectivo -el urbano- tienen naturalmente preeminencia sobre el proyecto arquitectónico y nos recuerdan que las relaciones espaciales que se "entretejen" con el sitio siempre son más determinantes que el propio edificio.

A través de la selección de Rosario se establece un hilo conductor que articula el carácter disidente de los arquitectos de esta ciudad. Más libres, desprejuiciados y excéntricos, geométrica y geográficamente hablando. Rescatamos a tres arquitectos. Sus obras, su discurso, o su personalidad, según el caso, marcan esa condición alternativa, de formas raras, "más que discutibles"W, con un fuerte arraigo en la tradición constructiva y, al mismo tiempo, un espíritu evolutivo marcado por la permanente búsqueda de la innovación.

Por último, en Córdoba, sus sierras, el entorno natural que rodea y caracteriza a la ciudad, ha sido, en los últimos años, el escenario de un gran desarrollo inmobiliario en torno a la vivienda. Diferentes usos del suelo, privado o público, han definido nuevas relaciones entre Arquitectura y Naturaleza condicionando, de esta manera, nuevas estrategias para la construcción del paisaje.

Bajo esta mirada los dos proyectos seleccionados desarrollan una sensibilidad especial.

Su presencia define claramente la huella del hombre y la arquitectura como hecho cultural; explica el lugar, su estructura material, su tradición constructiva y su topografía escabrosa.

En el interior, una segunda fachada, que ya no es la arquitectura, es la sierra, los reflejos, el agua, las montañas lejanas, las aves y el viento, nos hacen olvidar el fuerte impacto inicial de la arquitectura. Ya todo es contacto con la naturaleza, todo es luz, árboles y madera, carpinterías y techos. La arquitectura está íntimamente vinculada a la experiencia del lugar.

Y como si de arquitectura se tratase rita_a través del viaje pretende también estar íntimamente ligada a la experiencia del lugar.

\section{Roberto Busnelli \\ Arturo Franco}

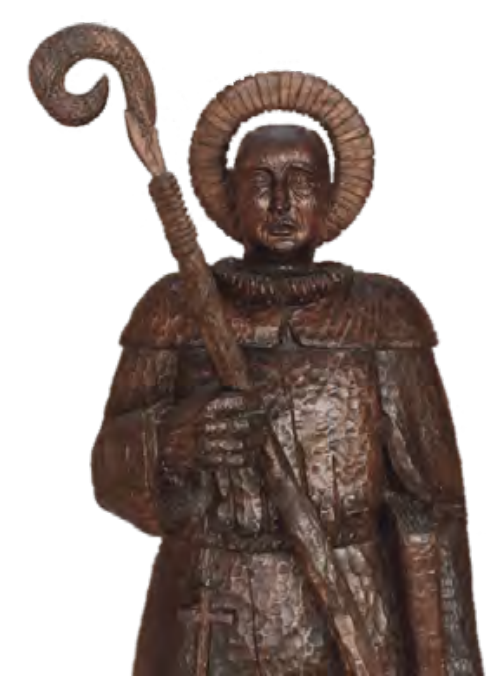

